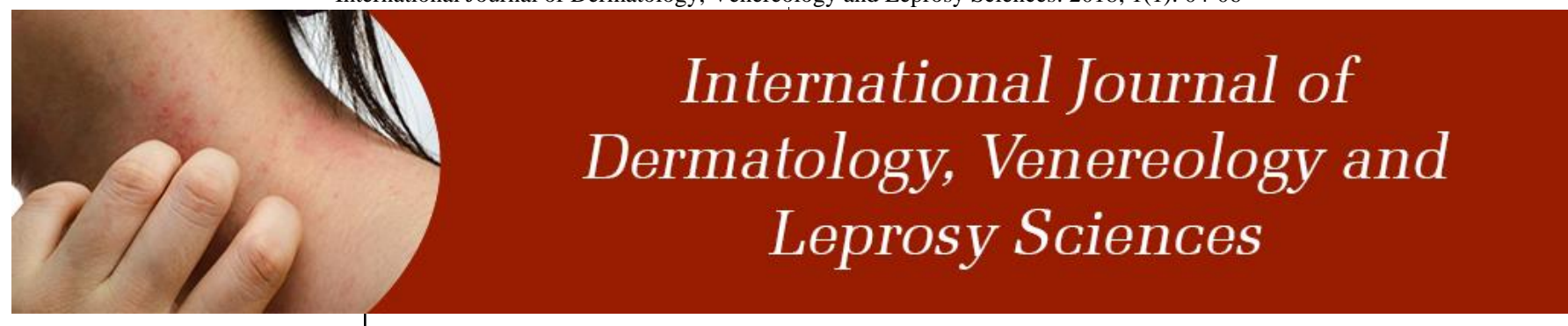

E-ISSN: 2664-942X P-ISSN: 2664-9411 www.dermatologypaper.com/ Derma 2018; 1(1): 04-06 Received: 05-05-2018 Accepted: 08-06-2018

Dr. Ritika Kaur Department of Dermatology, Government Medical College \& Hospital, Chandigarh, India
Corresponding Author: Dr. Ritika Kaur Department of Dermatology, Government Medical College \& Hospital, Chandigarh, India

\section{Occurrence of erythroderma among study patients: A clinical study erythroderma}

\section{Dr. Ritika Kaur}

DOI: https://doi.org/10.33545/26649411.2018.v1.i2a.10

\begin{abstract}
Background: Erythroderma is a rare skin disorder characterized by erythema and scaling. The present study aimed at recording cases of Erythroderma in the department.

Materials \& Methods: The present study was conducted in the department of Dermatology. It comprised of 52 cases of Erythroderma reported to the department. In all patients, epidemiological, clinical, laboratory and histological findings were recorded. The reason for the disease was recorded.

Results: Out of 52 patients, males were 32 and females were 20. Age group 11-20 years had 3, 21-30 years had 7, 31-40 years had 26, 41-50 years had 14 and 51-60 years had 2 cases. The difference was significant $(P<0.05)$. Causes were drug induced I 16, atopic in 12, Erythtrodermic psoriasis in 10, idiopathic in 5, Mycosis fungoides in 4, Allergic contact dermatitis in 3 and lichen planus in 2. The difference was significant $(P<0.05)$.

Conclusion: Most common cause was drug induced followed by a topic. Maximum cases were seen in age group 31-40 years.
\end{abstract}

Keywords: allergic contact dermatitis, erythroderma, skin

\section{Introduction}

Erythroderma or Exfoliative dermatitis is a rare skin disorder characterized by erythema and scaling involving $>90 \%$ of body surface area. Erythroderma is not a specific diagnosis but the clinical manifestation of a variety of underlying diseases. The estimated annual incidence is 1 to 2 patients per 100,000 population. It is more common in males and is usually seen in elderly patients however age of onset is primarily related to etiology. Most cases of erythroderma in younger patients are due to atopic dermatitis. Many times erythroderma is the manifestation of an underlying skin disorder like psoriasis, atopic dermatitis, pityriasis rubra pilaris or actinic Dermatosis.

Erythroderma is the result of a dramatic increase in the epidermal turnover rate. In patients with this disorder, the mitotic rate and the absolute number of germinative skin cells are higher than normal. Moreover, the time necessary for cells to mature and travel through the epidermis is decreased. This compressed maturation process results in an overall greater loss of epidermal material, which is manifested clinically as severe scaling and shedding.

Its etiology is very diverse including a variety of inflammatory dermatomes (atopic dermatitis, eczema, pityriasis rubra pilaris, psoriasis, etc.), cutaneous T-cell lymphoma (mycosis fungoides and Sezary Syndrome), as well as drug-induced forms, hematological or internal malignancies, and other diseases. Therefore, histological investigation represents a fundamental aid in the differential diagnosis of erythroderma, often being mandatory. However, in erythroderma subjects, the results of histological examination can be nonspecific, only showing hyperkeratosis, par keratosis, acanthosis, and chronic inflammatory infiltrate with or without eosinophil's. The present study aimed at recording cases of Erythroderma in the department.

\section{Materials \& Methods}

The present study was conducted in the department of Dermatology. It comprised of 52 cases of Erythroderma reported to the department of both genders. All were informed and written consent was obtained. Ethical approval was obtained prior to the commencement of the study.

Data such as name, age, gender etc. was recorded. In all patients, epidemiological, clinical, laboratory and histological findings were recorded. The reason for the disease was recorded. 
Results thus obtained were subjected to statistical analysis. $P$ value less than 0.05 was considered significant.

\section{Results}

Table 1: Distribution of patients

\begin{tabular}{|c|c|c|}
\hline \multicolumn{3}{|c|}{ Total- 52 } \\
\hline Gender & Males & Females \\
\hline Number & 32 & 20 \\
\hline
\end{tabular}

Table I shows that out of 52 patients, males were 32 and females were 20 .
Table 2: Age wise distribution of cases

\begin{tabular}{|c|c|c|}
\hline Age group (Years) & Number & \multirow{2}{*}{ P value } \\
\hline $11-20$ & 3 & \multirow{2}{*}{0.01} \\
\hline $21-30$ & 7 & \\
\hline $31-40$ & 26 & \\
\hline $41-50$ & 14 & \\
\hline $51-60$ & 2 & \\
\hline
\end{tabular}

Table II, graph I shows that age group 11-20 years had 3, 21-30 years had 7, 31-40 years had 26, 41-50 years had 14 and 51-60 years had 2 cases. The difference was significant $(P<0.05)$.

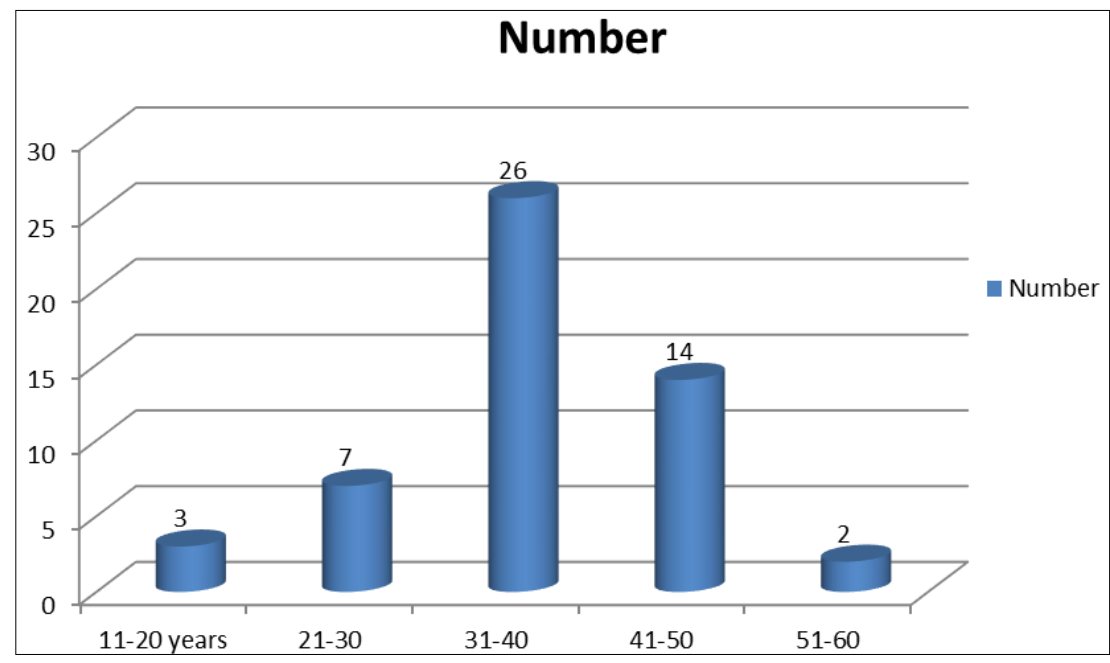

Fig 1: Age wise distribution of cases

Table 3: Causes of Erythroderma

\begin{tabular}{|c|c|c|}
\hline Causes & Number & \multirow{2}{*}{ P value } \\
\hline Drug induced & 16 & \\
\hline Atopic & 12 & \multirow{2}{*}{0.01} \\
\hline Erythtrodermic psoriasis & 10 \\
\hline Idiopathic & 5 \\
\hline Mycosis fungoides & 4 \\
\hline Allergic contact dermatitis & 3 \\
\hline Lichen planus & 2 & \\
\hline
\end{tabular}

Table III, graph II shows that causes were drug induced I 16, atopic in 12, Erythtrodermic psoriasis in 10, idiopathic in 5, Mycosis fungoides in 4, Allergic contact dermatitis in
3 and lichen planus in 2 . The difference was significant $(\mathrm{P}<$ $0.05)$.

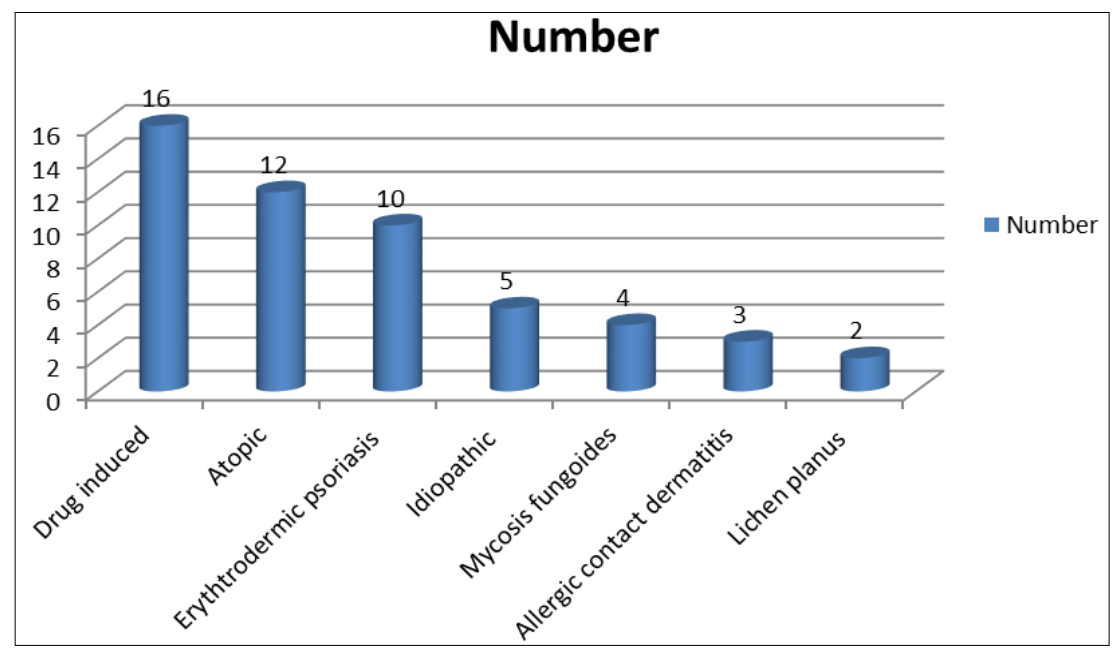

Fig 3: Causes of Erythroderma 


\section{Discussion}

Erythroderma, first described by Hebra in 1868 , is a reaction pattern characterized by generalized and confluent erythema with desquamation affecting more than $90 \%$ of body surface area and is usually accompanied by other systemic manifestations resulting in hemodynamic and metabolic derangements. Erythroderma is a rare Exfoliative skin disorder, the true incidence of which remains unknown. It is uncommon with an incidence of 1-2/100,000 population. Erythroderma is rarer in children where it accounts for approximately $0.1 \%$ of cases attending pediatric dermatology clinics. A prospective study done by Sehgal and Srivastava in India determined the incidence to be 35 per 100,000 dermatologic patients. There is a male predominance in most studies with a male-to-female ratio ranging from 2:1 to $4: 1$ and the mean age between 40 to 60 years. The present study aimed at recording cases of Erythroderma in the department.

In this study, out of 52 patients, males were 32 and females were 20. Age group 11-20 years had 3, 21-30 years had 7, 31-40 years had 26, 41-50 years had 14 and 51-60 years had 2 cases. Shirazi et al. found that the mean age of presentation was 39.3 years and male to female ratio was 3:2. Apart from erythema and scaling that were present in all patients, pruritis $(n=40,69 \%)$, edema $(n=12,20.2 \%)$ and fever $(n=11,19 \%)$ were the most common symptoms at presentation. The most common etiology of Exfoliative dermatitis was drug reactions $(n=19,32.7 \%)$ followed by atopic dermatitis $(\mathrm{n}=12,20.6 \%)$ and erythroderma psoriasis $(n=10,7.2 \%)$. Other causes were Mycosis Fungoides, Allergic/Air borne contact dermatitis, Lichen Planus, Pityriasis Rubra Pilaris. There was no significant contribution of laboratory data and all the patients were HIV negative. The best clinicopathological correlation (100\%) was found in Erythtrodermic psoriasis and Mycosis Fungoides.

We found that causes were drug induced I 16, atopic in 12, Erythtrodermic psoriasis in 10, idiopathic in 5, Mycosis fungoides in 4, Allergic contact dermatitis in 3 and lichen planus in 2. Benerjee et al. ${ }^{[10]}$ found that male preponderance was present and most of them were in the 4th or 5th decade. Etiologically the patients were divided into secondary erythroderma developing over pre-existing dermatoses, and idiopathic erythroderma. Secondary erythroderma $(n=24)$ cases outnumbered the idiopathic cases $(n=8)$. Among the pre- existing dermatoses, psoriasis was found to be the most common etiologic agent. Apart from erythema the other common presenting features were scaling and itching. Histopathological categorization was possible in $59.3 \%$ cases, rest of the cases showed non- ${ }^{-}$specific dermatitis. The most common histopathologic diagnosis was psoriasis (21.8\% of cases).

Sigurdsson et al. ${ }^{[11]}$ found that blinded histopathology examination alone was able to give the correct diagnosis in $61 \%(n=50 / 82)$ of cases when compared to final diagnosis. A diagnosis of psoriasis was made in $23.2 \%(\mathrm{n}=19 / 82)$ of subjects, spongiotic dermatitis/eczema in $20.7 \%(n=17 / 82)$, mycosis fungoides in $8.5 \%(\mathrm{n}=7 / 82)$, and drug eruption in 8.5\%; histological diagnosis was inconclusive or not matching the final diagnosis when available in the remaining $39.1 \%$ of cases $(n=32 / 82)$.

Shegal ${ }^{[12]}$ stated that since it can be the consequence of several conditions, mainly skin disorders, drug consumption and, more rarely, some malignancies, it is of indisputable importance to know the etiology to facilitate its management. However, despite these factors, erythroderma is still poorly studied in literature. Erythroderma patients usually undergo skin biopsies even if conflicting views about the diagnostic value and utility of skin biopsy in the investigation of Erythtrodermic patients still exist. Indeed, no diagnostic biopsies may be possible in erythroderma subjects, and clinical and pathological correlation may be a very complicated task.

\section{Conclusion}

Maximum cases were seen in age group 31-40 years. Most common cause was drug induced followed by atopic.

\section{References}

1. Frost P, Van Scott EJ. Ichthyosiformdermatoses. Arch Dermatol. 1966; 94:113.

2. Akhyani M, Ghodsi ZS, Toosi S, Dabbaghian H. Erythroderma: A clinical study of 97 cases. BMC Dermatol. 2005; 5:5.

3. Jowker F, Aslani FS, Shafiee M. Erythroderma: A clinicopathological study of 102 cases. J Pak Assoc Dermatol. 2006; 16:129- 33.

4. Sigurdsson V, Toonstra J, Hezemans- Boer M, van Vloten WA. Erythroderma. A clinical and follow- up study of 102 patients, with special emphasis on survival. J Am Acad Dermatol. 1996; 35:53- 7.

5. Bharatiya PR, Joshi PB. Study of exfoliative dermatitis. Indian J Dermatol Venereal Leprol. 1995; 61:81-3.

6. Vanconcellos C, Dominques PP, Aoki V, Miyake RK, Sauaia N, Martins JE et al. Erythroderma: Analysis of 247 cases. Rev Sauda Publica. 1995; 29:177-82.

7. Botella-Estrada R1, Sanmartin O, Oliver V, Febrer I, Aliaga A. Erythroderma. A clinicopathological study of 56 cases. Arch Dermatol. 1994; 130:1503-7.

8. Sehgal VN, Strivastava G, Sardana K. Erythroderma/exfoliative dermatitis: A synopsis. Int J Dermatol. 2004; 43:39- 47.

9. Mittal RR, Walia RL, Gill SS, Mangla R. Clinicopathological correlation in 50 cases of erythroderma. Indian $\mathbf{J}$ Dermatol Venereol Leprol. 1996; 62:351-3.

10. Banerjee S, Ghosh S, Mandal RK. A study of correlation between clinical and histopathological findings of erythroderma in North Bengal population. Indian J Dermatol. 2015; 60:549-55.

11. Sigurdsson V, Stegmans PH, Vloten WA van. The incidence of erythroderma: A survey among all dermatologists in the Netherland. J Am Acad Dermatol. 2001; 45:675-8.

12. Shegal VN, Srivastava G. Exfoliative Dermatitis: A prospective study of 80 patients. Dermatologica. 1986; $173: 278-84$ 